\title{
Immunogenic tumor cell death induced by chemotherapy in patients with breast cancer and esophageal squamous cell carcinoma
}

\author{
KEITA AOTO $^{1,3}$, KOUSAKU MIMURA ${ }^{2,3}$, HIROKAZU OKAYAMA ${ }^{1,3}$, MOTONOBU SAITO $^{1,3}$, SHUN CHIDA $^{1,3}$, \\ MASARU NODA ${ }^{1,3}$, TAKAHIRO NAKAJIMA ${ }^{1,3}$, KATSUHARU SAITO ${ }^{1,3}$, NORIKO ABE ${ }^{1}$, SHINJI OHKI ${ }^{1,3}$, \\ TOHRU OHTAKE ${ }^{1}$, SEIICHI TAKENOSHITA ${ }^{1,4}$ and KOJI KONO ${ }^{1-3}$ \\ Departments of ${ }^{1}$ Organ Regulatory Surgery, ${ }^{2}$ Advanced Cancer Immunotherapy, ${ }^{3}$ Gastrointestinal Tract Surgery and \\ ${ }^{4}$ Advanced Clinical Research Center, Fukushima Medical University, Fukushima 960-1295, Japan
}

Received May 15, 2017; Accepted October 18, 2017

DOI: 10.3892/or.2017.6097

\begin{abstract}
It has been reported that chemo-radiotherapy can induce immunogenic tumor cell death (ICD), which triggers T-cell immunity mainly mediated by high-mobility group box 1 protein (HMGB1) and calreticulin. However, there is still limited information to support this theory relating to chemotherapy alone. In the present study, the expression of HMGB1 and calreticulin was evaluated by immunohistochemistry in pre-treatment biopsy specimens and surgically resected specimens, which were obtained from patients with breast cancer $(n=52)$ and esophageal squamous cell carcinoma (ESCC) $(n=8)$ who had been treated with neoadjuvant chemotherapy (NAC). We also analyzed HMGB1 and calreticulin expression in breast cancer cell lines treated with chemotherapeutic drugs. As a result, both HMGB1 and calreticulin expression levels were significantly upregulated after NAC in both breast cancer and ESCC tissues. However, no significant correlation was observed between HMGB1 expression and pathological response after NAC or between HMGB1 expression and patient survival. Furthermore, although overall survival in the high infiltration group of CD8-positive $\mathrm{T}$ cells was significantly superior to that in the low infiltration group in breast cancer patients, there were no correlations
\end{abstract}

Correspondence to: Dr Kousaku Mimura, Department of Advanced Cancer Immunotherapy, Fukushima Medical University, 1 Hikarigaoka, Fukushima City, Fukushima 960-1295, Japan

E-mail: kmimura@fmu.ac.jp

Abbreviations: CRT, chemo-radiotherapy; DCs, dendritic cells; ESCC, esophageal squamous cell carcinoma; HMGB1, high-mobility group box 1 protein; ICD, immunogenic tumor cell death; NAC, neoadjuvant chemotherapy; TLR, Toll-like receptor

Key words: calreticulin, chemotherapeutic drugs, immunogenic tumor cell death, HMGB1, neoadjuvant chemotherapy between the number of CD8-positive T cells and HMGB1 or calreticulin expression levels. In addition, chemotherapeutic drugs induced upregulation of HMGB1 and calreticulin in all tested cell lines. Our findings indicate that chemotherapy alone can significantly induce ICD regardless of the degree of pathological response after chemotherapy.

\section{Introduction}

Breast cancer and esophageal squamous cell carcinoma (ESCC) are well known to be sensitive to chemotherapy and/or radiotherapy, and their combination with surgery has been proven to have clinical benefits (1-6). A multidisciplinary procedure including chemotherapy, radiotherapy and surgery is regarded as standard care for breast cancer and ESCC patients. In clinical practice, in such patients it is generally accepted that there are responders and non-responders to chemotherapy with or without radiotherapy, and limited information exists describing the mechanisms and biomarkers to predict the responders.

Although chemo-radiotherapy (CRT) is aimed at directly inducing apoptosis or necrosis, there is accumulating evidence to support the novel concept that CRT may induce the immunogenic tumor cell death (ICD) of tumor cells (7-18). CRT could trigger uptake of antigenic components by dendritic cells (DCs) and transfer antigenic signals to T-cell-mediated immunity, resulting in the expansion of antigen-specific cytotoxic $\mathrm{T}$ lymphocytes and production of tumor-specific monoclonal antibodies (mAbs). We and others have shown that high-mobility group box 1 protein (HMGB1) and calreticulin induced by cytotoxic stresses such as CRT are important mediators to induce ICD (19). However, whether ICD can be induced by chemotherapy alone in the clinical setting remains unclear.

Here, we evaluated i) whether expression of HMGB1 and calreticulin correlates with clinical outcomes in response to chemotherapy, ii) whether the number of CD8-positive $\left(\mathrm{CD} 8^{+}\right)$ T cells correlates with expression of HMGB1 and calreticulin, and iii) whether chemotherapy alone upregulates HMGB1 and calreticulin in clinical and in vitro settings. 


\section{Materials and methods}

Patients and samples. The expression levels of HMGB1, calreticulin, and CD8 were evaluated by immunohistochemistry in pre-treatment biopsy specimens and surgically resected specimens obtained from breast cancer patients $(\mathrm{n}=52)$ and ESCC patients $(\mathrm{n}=8)$ who had undergone treatment with neoadjuvant chemotherapy (NAC) between 2005 and 2015 at the Department of Organ Regulatory Surgery, Fukushima Medical University Hospital. Clinical and pathological information was retrospectively obtained by review of the medical records, with the last follow-up being in February 2016. Overall survival (OS) was defined as the period from the date of surgery to the date of death. The median follow-up time was 51.0 months. The study was conducted in accordance with the Declaration of Helsinki and was approved by the Institutional Review Board of Fukushima Medical University (reference 2329 for ESCC and 2444 for breast cancer).

Cell lines. Breast cancer cell lines, MDA-MB-231 [estrogen receptor (ER)-negative and HER2-negative], MCF-7 (ER-positive and HER2-negative) and SK-BR-3 (ER-negative and HER2-positive) were obtained as previously described (20), and cultured in RPMI-1640 medium with $10 \%$ fetal calf serum (FCS), $50 \mathrm{U} / \mathrm{ml}$ penicillin and $50 \mu \mathrm{g} / \mathrm{ml}$ streptomycin.

Immunohistochemistry. HMGB1, calreticulin and CD8 immunostaining was conducted using the avidin-biotin-peroxidase complex method. Each paraffin section was dewaxed, followed by antigen retrieval with Target Retrieval Solution (10 mmol citrate buffer at pH 6.0; Dako, Glostrup, Denmark) in an autoclave $\left(121^{\circ} \mathrm{C}, 15 \mathrm{~min}\right)$. The sections were cooled at room temperature for $30 \mathrm{~min}$ and endogenous peroxidase was blocked with $3 \%$ hydrogen peroxide. Thereafter, the sections were incubated with diluted normal blocking serum for $20 \mathrm{~min}$ and incubated with one of the following: mouse anti-human HMGB1 mAb (cat. no. SAB1403925, clone 2F6, $3 \mathrm{mg} / \mathrm{ml}$; Sigma-Aldrich, Tokyo, Japan) overnight at $4^{\circ} \mathrm{C}$; mouse anti-human calreticulin $\mathrm{mAb}$ (cat. no. ab22683, $5 \mathrm{mg}$ / $\mathrm{ml}$; Abcam, Cambridge, $\mathrm{UK}$ ) for $2 \mathrm{~h}$ at $37^{\circ} \mathrm{C}$; or mouse antihuman CD8 mAb (cat. no. M7103, $1.6 \mu \mathrm{g} / \mathrm{ml}$; Dako) overnight at $4^{\circ} \mathrm{C}$. Thereafter, the EnVision kit (cat. no. K4001; Dako) was used for anti-mouse secondary antibody staining according to the manufacturer's protocol and 3,3'-diaminobenzidine was used to detect specific bindings. The grade of HMGB1 and calreticulin expression was scored as 0 ( $0-10 \%$ positive), $1+(>10-30 \%$ positive), $2+(>30-80 \%$ positive), or $3+(>80 \%$ positive) in tumor cells (Fig. 1) in serial sections using five randomly selected areas at a magnification of $x 400$. The CD8 $8^{+}$ $\mathrm{T}$ cells were expressed as the mean values in four randomly selected areas at a magnification of $x 400$. Microscopic analyses were evaluated independently by two investigators (K.A. and K.K.) who had no prior knowledge of the clinical data.

In vitro treatments of breast cancer cell lines with chemotherapeutic drugs. Three breast cancer cell lines, MDA-MB-231, MCF-7, and SK-BR-3, were incubated with RPMI-1640 medium in 6-well plates. Tumor cells were grown to subconfluency and treated with chemotherapeutic drugs, paclitaxel (0.1-1 $\mu \mathrm{M})$ or doxorubicin $(0.1-1 \mu \mathrm{M})$, in serum-free medium
(AIM V ${ }^{\circledR}$; Thermo Fisher Scientific, Inc., Wilimington, DE, USA) on day 0 . Dying cells were analyzed by Annexin V and 7-aminoactinomycin D (7-AAD) (both from BD Pharmingen, San Jose, CA, USA) by flow cytometry, and the proportion of dying cells was determined using either Annexin V-positive or 7-AAD-positive cells. Supernatants of treated breast cancer cell line cultures were measured for HMGB1 contents by ELISA (Shino-Test Corporation, Tokyo, Japan), and cell surface expression of calreticulin was evaluated by flow cytometry with R-phycoerythrin-conjugated anti-calreticulin mAb (Enzo Life Sciences, Farmingdale, NY, USA).

Statistical analysis. A paired t-test was used to determine the differences in the HMGB1 score, calreticulin score, and the number of $\mathrm{CD} 8^{+} \mathrm{T}$ cells before and after NAC. A Chi-square test was used for the evaluation between chemo-response and HMGB1 score, calreticulin score, and the number of CD8 ${ }^{+}$ $\mathrm{T}$ cells, as well as between the number of $\mathrm{CD} 8^{+} \mathrm{T}$ cells and both HMGB1 and calreticulin scores. An unpaired t-test was used to determine HMGB1 and calreticulin expression between the control cell lines and the target cell lines treated with chemotherapeutic drugs. Cumulative survival was estimated by the Kaplan-Meier method, and the differences between the two groups were analyzed by a log-rank test. All statistical analyses were two-sided and conducted using Graphpad Prism v6.0 (Graphpad Software, Inc., La Jolla, CA, USA). P-values $<0.05$ were considered statistically significant.

\section{Results}

$H M G B 1$ and calreticulin expression before and after NAC. To evaluate HMGB1 and calreticulin expression within the tumor microenvironment induced by chemotherapy alone, immunohistochemical analysis was conducted in pre-treatment biopsy specimens and surgically resected specimens obtained from NAC-treated breast cancer and ESCC patients. Concerning NAC, breast cancer patients $(92 \%, n=48)$ were treated with 5-fluorouracil-epirubicin-cyclophosphamide (FEC or CEF) with/without docetaxel or paclitaxel, and trastuzumab was added for those with HER2-overexpressing tumors (Table I). All ESCC patients were treated with 5-fluorouracil + cisplatin. In order to semi-quantitatively evaluate HMGB1 and calreticulin expression, we classified the patients into 4 grades $(0$, $1+, 2+$ and $3+$ ), as described in Materials and methods section. The representative immunostainings using anti-HMGB1 and anti-calreticulin mAbs are shown in Fig. 1.

Both HMGB1 and calreticulin expression was significantly upregulated after NAC compared to pre-treatment samples in breast cancer and ESCC (Fig. 2). Summarized data from all samples showed that the degree of HMGB1 and calreticulin expression was significantly upregulated after NAC compared to the pre-treatment samples in breast cancer and ESCC (Fig. 3). Thus, it is strongly suggested that chemotherapy alone could upregulated HMGB1 and calreticulin expression in the tumor microenvironments in breast cancer and ESCC.

Correlation of HMGB1 and calreticulin expression with pathological responses after NAC and patient survival. Since the number of patients with breast cancer was enough to evaluate the clinical data, the evaluations of the response 
Table I. Clinical course and prognosis of the breast cancer cases depending on the chemotherapy regimen.

\begin{tabular}{|c|c|c|c|c|c|}
\hline Regimen & No. of patients & $\begin{array}{l}\text { No. of patients } \\
\text { with recurrence }\end{array}$ & $\begin{array}{l}\text { Relapse-free survival } \\
\text { [mean (range) months] }\end{array}$ & No. of deaths & $\begin{array}{c}\text { Overall survival } \\
\text { [mean (range) months] }\end{array}$ \\
\hline FEC + docetaxel & 14 & 2 & $32(8-108)$ & 1 & $34(1-114)$ \\
\hline FEC + paclitaxel & 14 & 5 & $53(1-114)$ & 3 & $65(3-114)$ \\
\hline $\begin{array}{l}\text { FEC + docetaxel } \\
+ \text { trastuzumab }\end{array}$ & 5 & 2 & $25(4-38)$ & 1 & $27(5-38)$ \\
\hline $\begin{array}{l}\text { FEC + paclitaxel } \\
\text { + trastuzumab }\end{array}$ & 5 & 2 & $70(22-96)$ & 1 & $76(53-96)$ \\
\hline FEC & 5 & 1 & $75(13-106)$ & 0 & $79(33-108)$ \\
\hline CEF & 4 & 2 & $73(15-104)$ & 1 & $70(18-104)$ \\
\hline $\begin{array}{l}\text { FEC + paclitaxel } \\
\text { + vinorelbine }\end{array}$ & 1 & 1 & 3 & 1 & 14 \\
\hline Docetaxel & 1 & 0 & 15 & 0 & 15 \\
\hline Paclitaxel + carboplatin & 1 & 0 & 45 & 0 & 45 \\
\hline Paclitaxel + cisplatin & 1 & 0 & 32 & 1 & 32 \\
\hline Paclitaxel + trastuzumab & 1 & 0 & 22 & 0 & 22 \\
\hline
\end{tabular}

FEC, 5-fluorouracil (500 mg/m², intravenous injection on day 1) -epirubicin (60-100 mg/m², intravenous injection on day 1) -cyclophosphamide $\left(500 \mathrm{mg} / \mathrm{m}^{2}\right.$, intravenous injection on day 1$) /$ every 3 weeks; CEF, cyclophsphamide $\left(75 \mathrm{mg} / \mathrm{m}^{2}\right.$, internal use on day $\left.1-14\right)$-epirubicin $\left(60 \mathrm{mg} / \mathrm{m}^{2}\right.$, intravenous injection on day 1 and 8$)-5$-fluorouracil $\left(500 \mathrm{mg} / \mathrm{m}^{2}\right.$, intravenous injection on day 1 and 8$) /$ every 4 weeks.

A

HMGB1
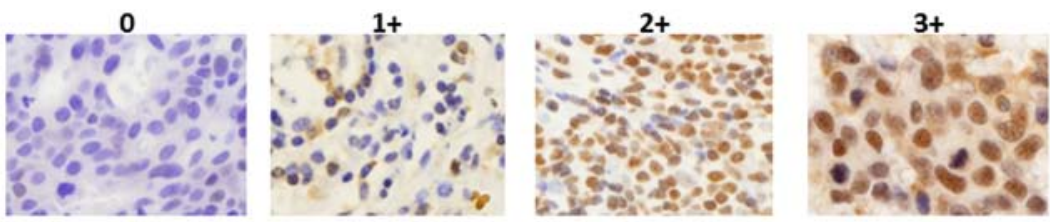

Calreticulin
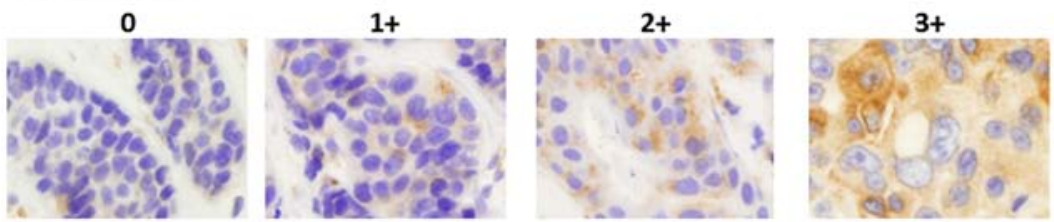

\section{B}

\section{HMGB1}
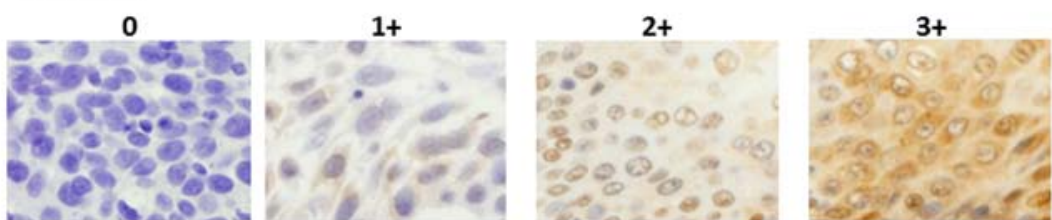

\section{Calreticulin}

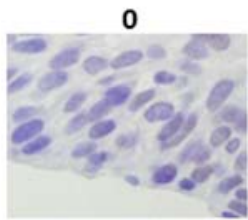

$1+$

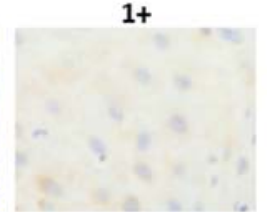

$2+$

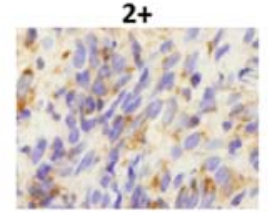

$3+$

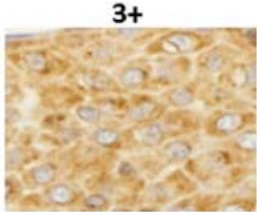

Figure 1. Representative immunostainings for HMGB1 and calreticulin in breast cancer (A) and ESCC (B) cases using anti-HMGB1, anti-calreticulin mAbs. The grade of HMGB1 and calreticulin expression was scored as $0(0-10 \%$ positive), $1+(>10-30 \%$ positive), $2+(>30-80 \%$ positive), or $3+(>80 \%$ positive) based on the tumor cells. Sections in individual sample were observed at a magnification of x400. HMGB1, high-mobility group box 1 protein; ESCC, esophageal squamous cell carcinoma. 
A

HMGB1

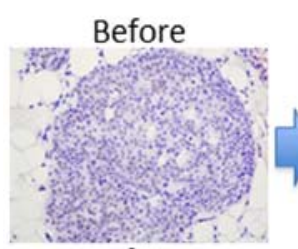

$1+$

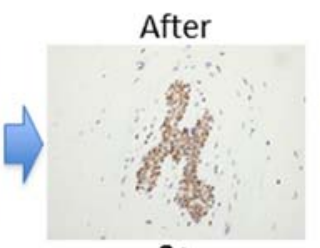

3+

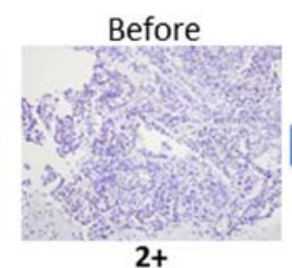

$2+$

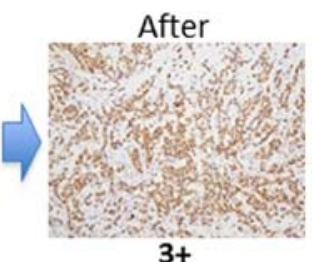

$3+$

\section{Calreticulin}
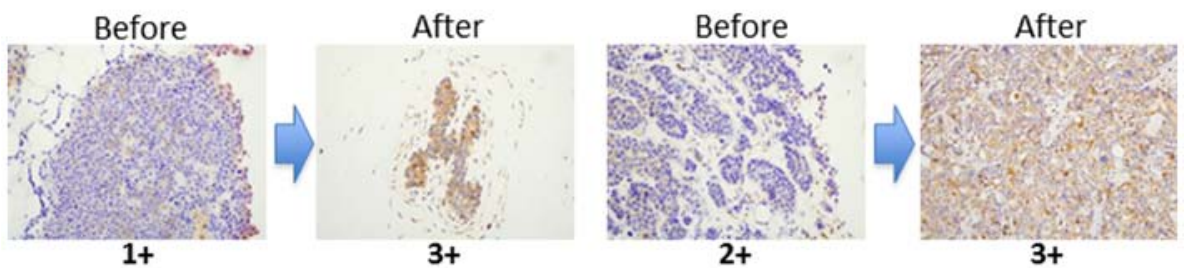

B

HMGB1

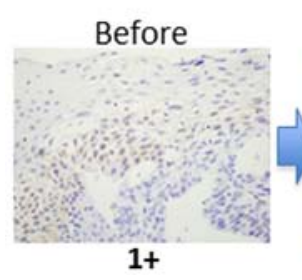

After

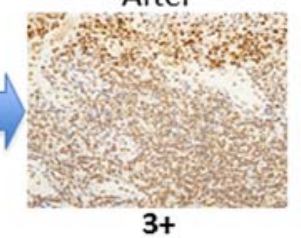

Calreticulin
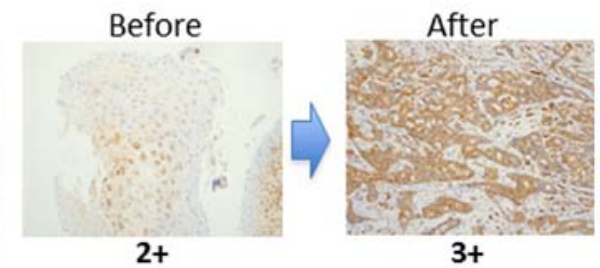

Figure 2. Representative immunostainings of HMGB1 and calreticulin before and after NAC in breast cancer (A) and ESCC (B) cases. Sections in individual samples were observed at a magnification of x400. HMGB1, high-mobility group box 1 protein; NAC, neoadjuvant chemotherapy; ESCC, esophageal squamous cell carcinoma.
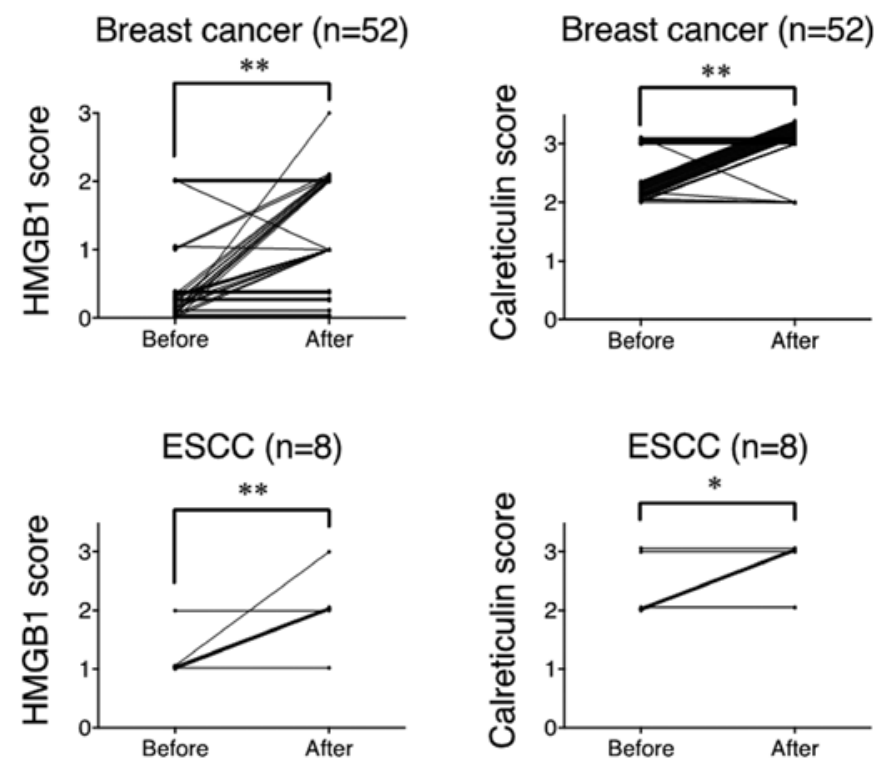

Figure 3. Summarized data for semi-quantitative evaluation of HMGB1 and calreticulin expression before and after NAC in breast cancer and ESCC cases. " $\mathrm{p}<0.05,{ }^{* *} \mathrm{p}<0.001$. HMGB1, high-mobility group box 1 protein; NAC, neoadjuvant chemotherapy; ESCC, esophageal squamous cell carcinoma.

rate and survival rate were performed in the breast cancer specimens only. Patient and tumor characteristics in the breast cancer cases are shown in Table II. Tumors were classified according to the TNM Classification of Malignant Tumors (UICC 7th edition) and histological criteria made by the Japanese Breast Cancer Society for assessment of therapeutic response was used to evaluate the pathological response to NAC (21). As shown in Table III, there was no significant correlation between HMGB1 score in the pre-treatment samples and pathological response, or between HMGB1 score in the post-treatment samples and pathological response. OS in the responder group to NAC was significantly superior to that in the non-responder group (Fig. 4A). However, there was no significant difference in survival between HMGB1-high and HMGB1-low scores in the pre-treatment samples or the posttreatment samples (Fig. 4B). Similarly, calreticulin expression in the pre- and post-treatment samples did not affect pathological response and OS (Table IV and Fig. 4C).

Correlation of infiltrating $C D 8^{+} T$ cells before and after NAC with HMGBI and calreticulin score, and patient survival in breast cancer patients. Representative immunostaining using CD8 mAb is shown in Fig. 5A. There was no significant correlation between the number of $\mathrm{CD} 8^{+} \mathrm{T}$ cells before and after NAC ( $p=0.9228)$ (Fig. 5A). Furthermore, there were no significant differences in the number of $\mathrm{CD} 8^{+} \mathrm{T}$ cells before and after NAC between the cases with pathological grade 0 and 1 or those with grade 2 and 3 (Fig. 5B). We next evaluated the correlation between the number of $\mathrm{CD}^{+} \mathrm{T}$ cells before/ after NAC and HMGB1 score before/after NAC, and no correlations were observed (Fig. 5C, left). Similarly, the number 
Table II. Patient and tumor characteristics of the breast cancer cases $(n=52)$.

\begin{tabular}{|c|c|}
\hline Characteristics & $\mathrm{n}$ \\
\hline \multicolumn{2}{|l|}{ Age (years) } \\
\hline Mean & 53.4 \\
\hline Range & $26-75$ \\
\hline \multicolumn{2}{|l|}{ Sex } \\
\hline Male & 1 \\
\hline Female & 51 \\
\hline \multicolumn{2}{|l|}{ Tumor ${ }^{\mathrm{a}}$} \\
\hline $\mathrm{T} 1$ & 7 \\
\hline $\mathrm{T} 2$ & 24 \\
\hline $\mathrm{T} 3$ & 7 \\
\hline $\mathrm{T} 4$ & 14 \\
\hline \multicolumn{2}{|l|}{ Lymph node metastasis ${ }^{\mathrm{a}}$} \\
\hline No & 2 \\
\hline N1 & 41 \\
\hline N2 & 7 \\
\hline N3 & 2 \\
\hline \multicolumn{2}{|l|}{ Stage $^{\mathrm{a}}$} \\
\hline I & 0 \\
\hline II & 27 \\
\hline III & 23 \\
\hline IV & 2 \\
\hline \multicolumn{2}{|l|}{ Histological classification } \\
\hline Invasive ductal carcinoma & 41 \\
\hline Non-invasive carcinoma & 1 \\
\hline Mucinous carcinoma & 2 \\
\hline Medullary carcinoma & 1 \\
\hline Metaplastic carcinoma & 2 \\
\hline Invasive micropapillary carcinoma & 1 \\
\hline Spindle cell carcinoma & 1 \\
\hline Others & 1 \\
\hline Missing & 2 \\
\hline \multicolumn{2}{|l|}{ Subtype } \\
\hline Luminal & 21 \\
\hline HER2 & 5 \\
\hline Triple-negative & 17 \\
\hline Luminal + HER2 & 8 \\
\hline
\end{tabular}

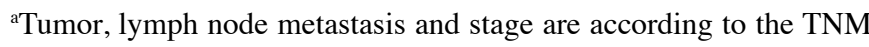
lassification for breast cancer (UICC, 7th edition).

of $\mathrm{CD}^{+} \mathrm{T}$ cells before/after NAC did not affect calreticulin score before/after NAC (Fig. 5C, right). However, OS rates in the high infiltration group of $\mathrm{CD}^{+} \mathrm{T}$ cells ( $>50$ counts/field) before and after NAC were significantly superior to those in the low infiltration group ( $<50$ counts/field) (Fig. 5D).

In vitro treatment of breast cancer cell lines with chemotherapeutic drugs. To further evaluate HMGB1 and calreticulin expression following treatment with
Table III. Correlation between HMGB1 score and pathological response.

\section{Before NAC}

\begin{tabular}{|c|c|c|}
\hline HMGB1 score & Grade 0,1 & Grade 2,3 \\
\hline 0 & 23 & 18 \\
\hline $1+$ & 2 & 4 \\
\hline $2+$ & 1 & 2 \\
\hline $3+$ & 0 & 0 \\
\hline P-value & \multicolumn{2}{|c|}{0.4648} \\
\hline
\end{tabular}

\section{After NAC}

HMGB1 score Grade $0,1 \quad$ Grade 2, 3

\begin{tabular}{llll}
\hline 0 & 5 & & 8 \\
$1+$ & 5 & & 6 \\
$2+$ & 8 & & 6 \\
$3+$ & 8 & & 4 \\
P-value & & 0.5076 &
\end{tabular}

HMGB1, high-mobility group box 1 protein; NAC, neoadjuvant chemotherapy.

Table IV. Correlation between calreticulin score and pathological response.

\section{Before NAC}

Calreticulin score

Grade 0,1

Grade 2, 3

\begin{tabular}{lrrr}
\hline 0 & 0 & & 0 \\
$1+$ & 0 & & 0 \\
$2+$ & 18 & & 17 \\
$3+$ & 8 & & 7 \\
P-value & & 0.9017 & \\
\hline
\end{tabular}

\section{After NAC}

\begin{tabular}{|c|c|c|}
\hline Calreticulin score & Grade 0,1 & Grade 2, 3 \\
\hline 0 & 0 & 0 \\
\hline $1+$ & 0 & 0 \\
\hline $2+$ & 3 & 3 \\
\hline $3+$ & 23 & 21 \\
\hline P-value & & \\
\hline
\end{tabular}

NAC, neoadjuvant chemotherapy.

chemotherapeutic drugs, three breast tumor cell lines were treated with paclitaxel or doxorubicin in vitro, and the production of HMGB1 and surface expression of calreticulin, along with the proportion of dying cells (Fig. 6A), were analyzed. As shown in Fig. 6B and C, chemotherapeutic drugs alone induced variable levels of HMGB1 production (Fig. 6B) 
A

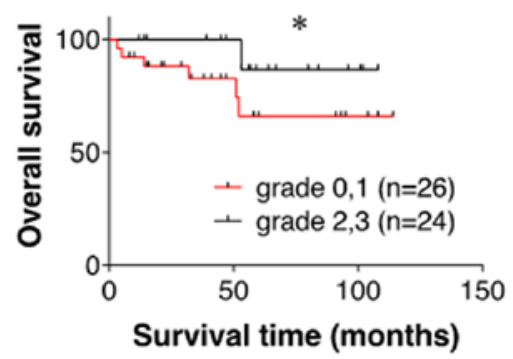

B

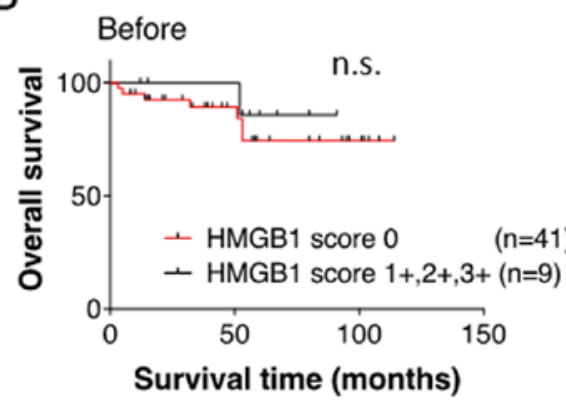

C

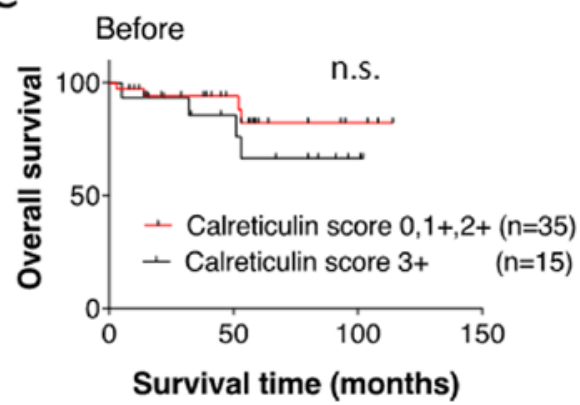

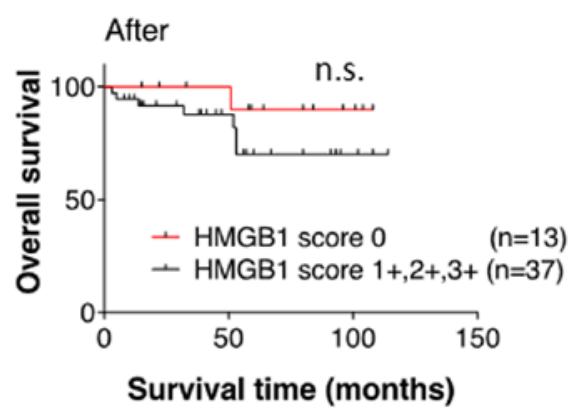

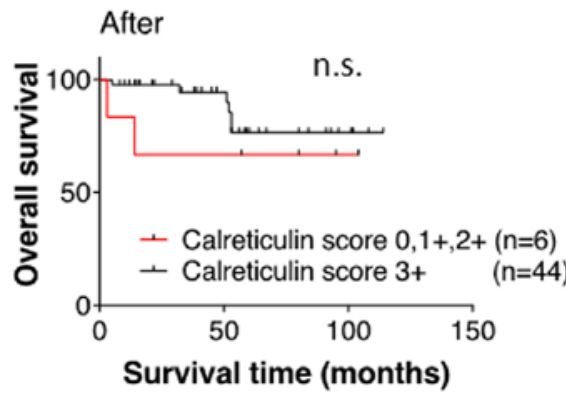

Figure 4. Pathological response and HMGB1/calreticulin expression as related to clinical outcomes in breast cancer patients. (A) Correlation of the pathological response to overall survival. (B) Correlation of the HMGB1 expression before NAC (left graph) and after NAC (right graph) to overall survival. (C) Correlation of calreticulin expression before NAC (left graph) and after NAC (right graph) to overall survival. " p<0.05. HMGB1, high-mobility group box 1 protein; NAC, neoadjuvant chemotherapy. n.s., not significant.

and surface calreticulin expression (Fig. 6C) depending on the drug and cell line, regardless of approximately the same proportion of dying cells.

\section{Discussion}

The present study contains novel findings supporting the concept that ICD can be induced by chemotherapy alone in patients with breast cancer and ESCC. Firstly, both HMGB1 and calreticulin expression were significantly upregulated after NAC. Secondly, chemotherapeutic drugs induced the upregulation of HMGB1 and calreticulin in several tested breast cancer cell lines.

We and others have recently reported that danger signals from dying cells following treatment with radiotherapy or certain chemotherapeutic drugs, such as anthracyclines and oxaliplatin, can induce Toll-like receptor (TLR)-dependent, antigen-specific T-cell immunity $(22,23)$. Additional therapeutic modalities shown to induce ICD include oncolytic virus therapy (24-26) and photodynamic therapy $(27,28)$. Furthermore, among various danger signals released from dying cells in a tumor-bearing mouse model, HMGB1, but not other known TLR4 ligands, could be a mandatory factor to induce tumor antigen-specific T-cell immunity $(22,23)$. Moreover, it has been shown that early membrane exposure of calreticulin induced by certain chemotherapeutic drugs, such as anthracyclines and oxaliplatin (15,23,29-31), could enhance the phagocytosis of dying tumor cells by DCs in vitro (32-34). Both HMGB1 release and calreticulin cell surface expression were found to be required for antigen-specific T-cell response in a murine model. In the present study, we showed for the first time in a human clinical study that conventional chemotherapy alone significantly induced the upregulation of HMGB1 and calreticulin in breast cancer and ESCC, indicating that some degree of ICD was significantly induced in the tumor microenvironment after chemotherapy. Contrary to expectations, no correlation was observed between these expression levels and the number of $\mathrm{CD}^{+} \mathrm{T}$ cells in the present study, although OS in the high infiltration group of $\mathrm{CD}^{+} \mathrm{T}$ cells was significantly superior to that in the low infiltration group in breast cancer patients. In addition, the present in vitro study indicated that there were substantial variations in HMGB1 and calreticulin 
A

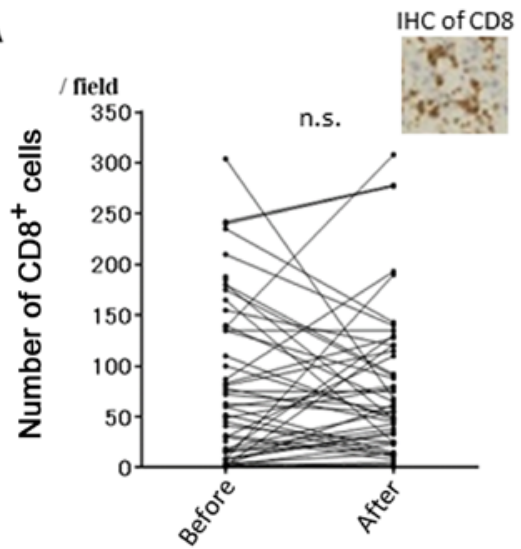

C

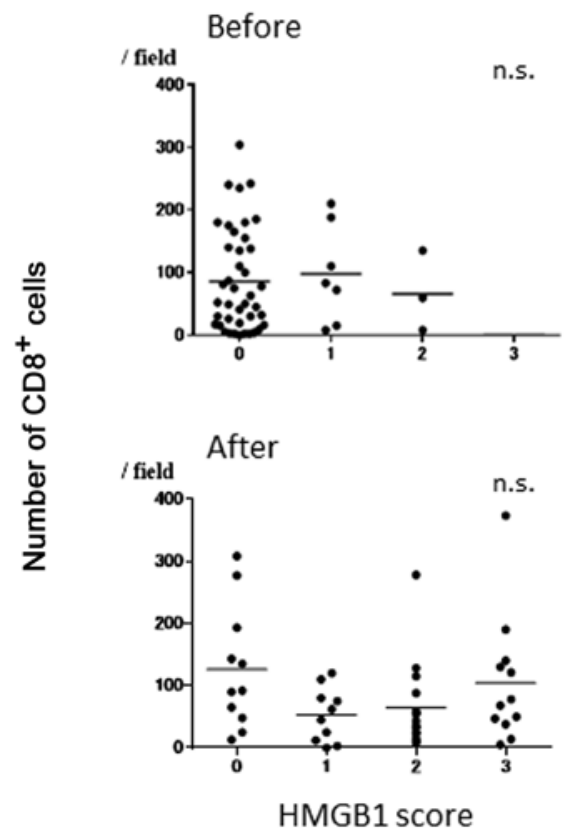

D

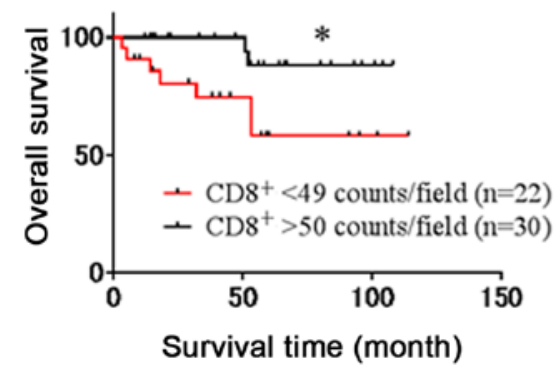

B

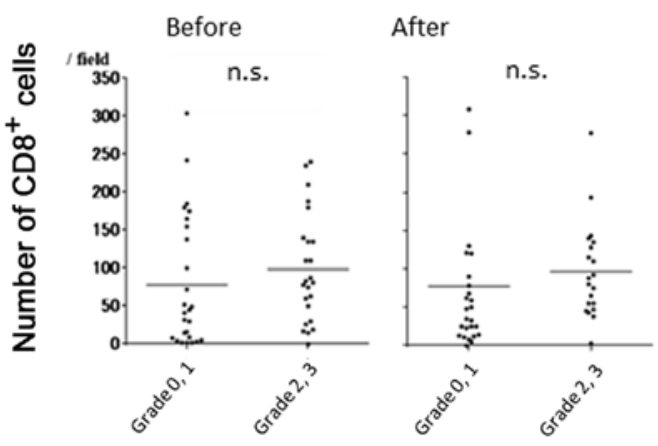

Before
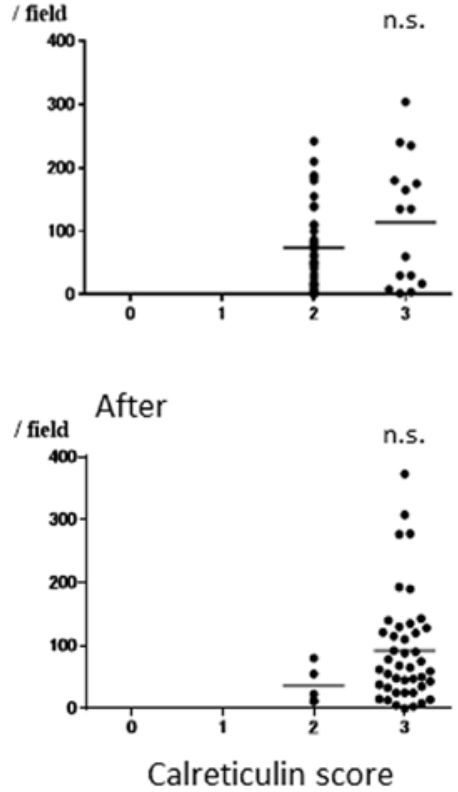

After

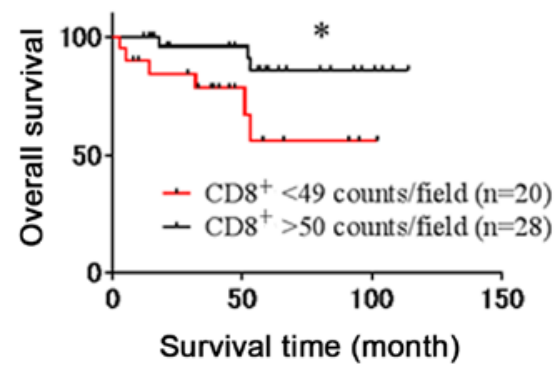

Figure 5. Correlation of the number of $\mathrm{CD}^{+} \mathrm{T}$ cells before and after NAC with the HMGB1 and calreticulin score, and patient survival in breast cancer patients. (A) Evaluation of the number of $\mathrm{CD}^{+} \mathrm{T}$ cells before and after NAC. Representative IHC of CD8 is shown. (B) Evaluation of the number of CD8 ${ }^{+} \mathrm{T}$ cells before and after NAC in pathological response. (C) Correlation of the HMGB1/calreticulin score with the number of CD8 ${ }^{+} \mathrm{T}$ cells before and after NAC. (D) Correlation of the degree of infiltrating $\mathrm{CD}^{+} \mathrm{T}$ cells before and after NAC with clinical outcomes. "p $<0.05$. HMGB1, high-mobility group box 1 protein; NAC, neoadjuvant chemotherapy. n.s. not significant.

production following chemotherapy in the breast cancer cell lines regardless of approximately the same proportion of dying cells. Apetoh et al reported that breast cancer patients with a TLR4 loss-of-function allele relapsed more quickly after chemotherapy than those with a normal TLR4 allele (23). This finding indicates a clinically relevant immune reaction triggered by TLR-dependent ICD induced by chemotherapy, and the possibility of predicting clinical outcome for CRT or chemotherapy by evaluating ICD status. However, in the present study, there was no significant correlation between the degree of mediators (HMGB1 and calreticulin) and pathological response after NAC, or between the degree of the mediators and patient survival. It is therefore likely that the induction of ICD alone is not a suitable biomarker to predict the clinical response to NAC, and a more complicated network is involved in ICD induction. Regarding this problem, 
A MDA-MB-231

MCF-7

SK-BR-3

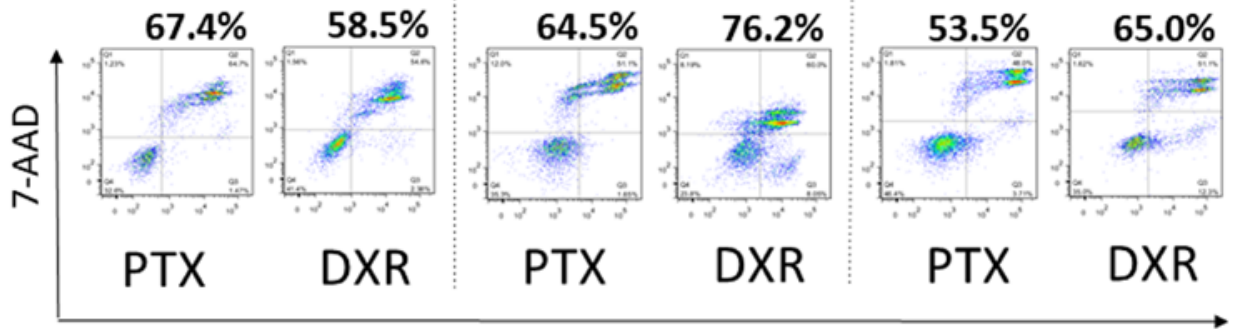

\section{PE Annexin V}
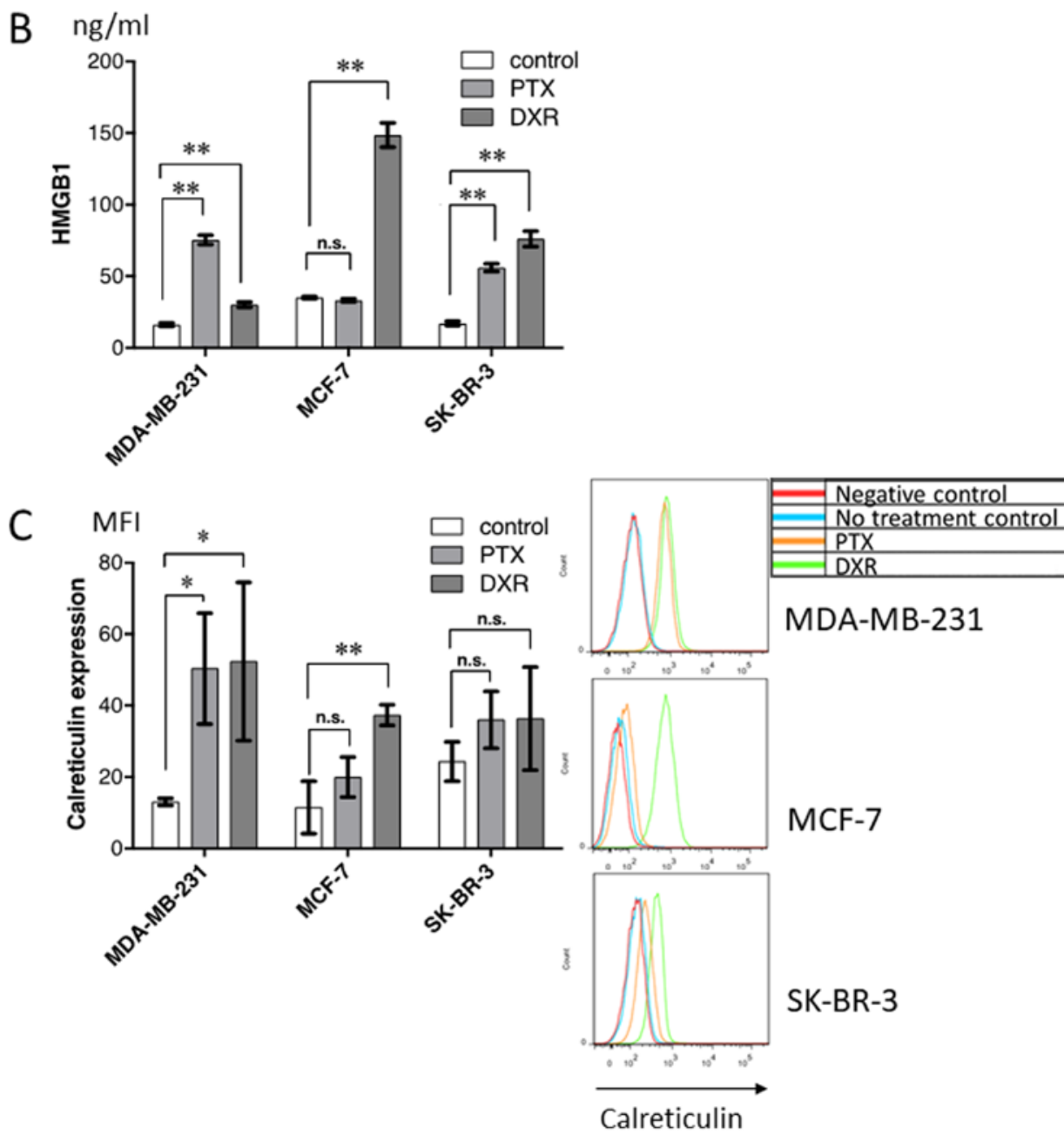

MDA-MB-231

MCF-7

SK-BR-3

Figure 6. In vitro treatment of breast cancer cell lines with chemotherapeutic drugs. (A) The proportion of dying cells [Annexin $\mathrm{V}(+)$ or $7-\mathrm{AAD}(+)]$ was analyzed by flow cytometry. (B) HMGB1 in the supernatant after chemotherapy was evaluated by ELISA. (C) Calreticulin expressed on the cell surface after chemotherapy was evaluated by flow cytometry. Representative histograms for these cell lines are shown. *p<0.05, ${ }^{* *}$ p $<0.001$. PTX, paclitaxel; DXR, doxorubicin; HMGB1, high-mobility group box 1 protein. n.s., not significant.

Bruchard et al, recently reported that myeloid-derived suppressor cells (MDSCs) treated with gemcitabine and 5 -fluorouracil produced IL-1 $\beta$, and MDSC-derived IL-1 $\beta$ induced secretion of IL-17 by CD4-positive T cells, leading to blunt the anticancer efficacy of the chemotherapy (35). Further investigation is required to find a suitable biomarker for the response to NAC.

Taking our present and previous studies into consideration (36), it is clear that some degree of ICD was induced in cancer patients after CRT or chemotherapy alone. Combination therapy of CRT or chemotherapy with immune checkpoint inhibitors may therefore induce a synergistic effect. It has been shown that the anti-CTLA4 antibody enhances the antigen presentation of DCs activated by HMGB1 and calreticulin, and that anti-programmed death 1/anti-programmed death ligand 1 antibodies enhance the cytotoxic ability of tumor antigen-specific T-cells in the tumor microenvironment, resulting in the improvement of patient survival $(37,38)$.

In conclusion, the findings of the present study indicate that chemotherapy alone can induce ICD in breast cancer and ESCC patients. Hence, a combination therapy of chemotherapy with immune checkpoint inhibitors may enhance the ICD, resulting in the improvement of both the pathological response and survival of breast cancer and ESCC patients. 


\section{References}

1. Ishikura S, Nihei K, Ohtsu A, Boku N, Hironaka S, Mera K, Muto M, Ogino T and Yoshida S: Long-term toxicity after definitive chemoradiotherapy for squamous cell carcinoma of the thoracic esophagus. J Clin Oncol 21: 2697-2702, 2003.

2. de Manzoni G, Pedrazzani C, Laterza E, Pasini F, Grandinetti A, Bernini M, Ruzzenente A, Zerman G, Tomezzoli A and Cordiano C: Induction chemoradiotherapy for squamous cell carcinoma of the thoracic esophagus: Impact of increased dosage on long-term results. Ann Thorac Surg 80: 1176-1183, 2005.

3. Early Breast Cancer Trialists' Collaborative Group (EBCTCG): Effects of chemotherapy and hormonal therapy for early breast cancer on recurrence and 15-year survival: An overview of the randomised trials. Lancet 365: 1687-1717, 2005.

4. Wolmark N, Wang J, Mamounas E, Bryant J and Fisher B Preoperative chemotherapy in patients with operable breast cancer: Nine-year results from National Surgical Adjuvant Breast and Bowel Project B-18. J Natl Cancer Inst Monogr 30 96-102, 2001.

5. Bear HD, Anderson S, Brown A, Smith R, Mamounas EP, Fisher B, Margolese R, Theoret H, Soran A, Wickerham DL, et al; National Surgical Adjuvant Breast and Bowel Project Protocol B-27: The effect on tumor response of adding sequential preoperative docetaxel to preoperative doxorubicin and cyclophosphamide: Preliminary results from National Surgical Adjuvant Breast and Bowel Project Protocol B-27. J Clin Oncol 21: 4165-4174, 2003.

6. Rastogi P, Anderson SJ, Bear HD, Geyer CE, Kahlenberg MS, Robidoux A, Margolese RG, Hoehn JL, Vogel VG, Dakhil SR et al: Preoperative chemotherapy: Updates of National Surgical Adjuvant Breast and Bowel Project Protocols B-18 and B-27. J Clin Oncol 26: 778-785, 2008.

7. Kono K and Mimura K: Immunogenic tumor cell death induced by chemoradiotherapy in a clinical setting. OncoImmunology 2 : e22197, 2013.

8. Kono K, Mimura K and Kiessling R: Immunogenic tumor cell death induced by chemoradiotherapy: Molecular mechanisms and a clinical translation. Cell Death Dis 4: e688, 2013.

9. Kroemer G, Galluzzi L, Kepp O and Zitvogel L: Immunogenic cell death in cancer therapy. Annu Rev Immunol 31: 51-72, 2013.

10. Krysko DV, Garg AD, Kaczmarek A, Krysko O, Agostinis P and Vandenabeele P: Immunogenic cell death and DAMPs in cancer therapy. Nat Rev Cancer 12: 860-875, 2012.

11. Krysko O, Løve Aaes T, Bachert C, Vandenabeele P and Krysko DV: Many faces of DAMPs in cancer therapy. Cell Death Dis 4: e631, 2013.

12. Ladoire S, Enot D, Andre F, Zitvogel L and Kroemer G: Immunogenic cell death-related biomarkers: Impact on the survival of breast cancer patients after adjuvant chemotherapy. OncoImmunology 5: e1082706, 2015

13. Stoll G, Enot D, Mlecnik B, Galon J, Zitvogel L and Kroemer G: Immune-related gene signatures predict the outcome of neoadjuvant chemotherapy. OncoImmunology 3: e27884, 2014.

14. Gebremeskel S and Johnston B: Concepts and mechanisms underlying chemotherapy induced immunogenic cell death: Impact on clinical studies and considerations for combined therapies. Oncotarget 6: 41600-41619, 2015.

15. Casares N, Pequignot MO, Tesniere A, Ghiringhelli F, Roux S, Chaput N, Schmitt E, Hamai A, Hervas-Stubbs S, Obeid M, et al Caspase-dependent immunogenicity of doxorubicin-induced tumor cell death. J Exp Med 202: 1691-1701, 2005

16. Wong DY, Ong WW and Ang WH: Induction of immunogenic cell death by chemotherapeutic platinum complexes. Angew Chem Int Ed Engl 54: 6483-6487, 2015.

17. Galluzzi L, Buqué A, Kepp O, Zitvogel L and Kroemer G: Immunological Effects of conventional chemotherapy and targeted anticancer agents. Cancer Cell 28: 690-714, 2015.

18. Hodge JW, Garnett CT, Farsaci B, Palena C, Tsang KY, Ferrone S and Gameiro SR: Chemotherapy-induced immunogenic modulation of tumor cells enhances killing by cytotoxic T lymphocytes and is distinct from immunogenic cell death. Int J Cancer 133: 624-636, 2013

19. Kepp O, Senovilla L, Vitale I, Vacchelli E, Adjemian S, Agostinis P, Apetoh L, Aranda F, Barnaba V, Bloy N, et al Consensus guidelines for the detection of immunogenic cell death. OncoImmunology 3: e955691, 2014.

20. Okano M, Kumamoto K, Saito M, Onozawa H, Saito K, Abe N, Ohtake T and Takenoshita S: Upregulated Annexin A1 promotes cellular invasion in triple-negative breast cancer. Oncol Rep 33: 1064-1070, 2015.
21. Masafumi K, Sadako A and Futoshi A: Y K, H M and S N: Histological criteria for assessment of therapeutic response in breast cancer (2007 version). Breast Cancer 15: 5-7, 2007.

22. Apetoh L, Ghiringhelli F, Tesniere A, Criollo A, Ortiz C, Lidereau R, Mariette C, Chaput N, Mira JP, Delaloge S, et al: The interaction between HMGB1 and TLR4 dictates the outcome of anticancer chemotherapy and radiotherapy. Immunol Rev 220: 47-59, 2007.

23. Apetoh L, Ghiringhelli F, Tesniere A, Obeid M, Ortiz C, Criollo A, Mignot G, Maiuri MC, Ullrich E, Saulnier P, et al: Toll-like receptor 4-dependent contribution of the immune system to anticancer chemotherapy and radiotherapy. Nat Med 13: 1050-1059, 2007.

24. Miyamoto S, Inoue H, Nakamura T, Yamada M, Sakamoto C, Urata Y, Okazaki T, Marumoto T, Takahashi A, Takayama K, et al: Coxsackievirus B3 is an oncolytic virus with immunostimulatory properties that is active against lung adenocarcinoma. Cancer Res 72: 2609-2621, 2012.

25. Diaconu I, Cerullo V, Hirvinen ML, Escutenaire S, Ugolini M, Pesonen SK, Bramante S, Parviainen S, Kanerva A, Loskog AS, et al: Immune response is an important aspect of the antitumor effect produced by a CD40L-encoding oncolytic adenovirus. Cancer Res 72: 2327-2338, 2012

26. Takasu A, Masui A, Hamada M, Imai T, Iwai S and Yura Y: Immunogenic cell death by oncolytic herpes simplex virus type 1 in squamous cell carcinoma cells. Cancer Gene Ther 23: 107-113, 2016.

27. Garg AD, Krysko DV, Verfaillie T, Kaczmarek A, Ferreira GB, Marysael T, Rubio N, Firczuk M, Mathieu C, Roebroek AJ, et al: A novel pathway combining calreticulin exposure and ATP secretion in immunogenic cancer cell death. EMBO J 31: 1062-1079, 2012.

28. Tanaka M, Kataoka H, Yano S, Sawada T, Akashi H, Inoue M, Suzuki S, Inagaki $\mathrm{Y}$, Hayashi $\mathrm{N}$, Nishie $\mathrm{H}$, et al: Immunogenic cell death due to a new photodynamic therapy (PDT) with glycoconjugated chlorin (G-chlorin). Oncotarget 7: 47242-47251, 2016.

29. Michaud M, Martins I, Sukkurwala AQ, Adjemian S, Ma Y, Pellegatti P, Shen S, Kepp O, Scoazec M, Mignot G, et al: Autophagy-dependent anticancer immune responses induced by chemotherapeutic agents in mice. Science 334: 1573-1577, 2011.

30. Zappasodi R, Pupa SM, Ghedini GC, Bongarzone I, Magni M, Cabras AD, Colombo MP, Carlo-Stella C, Gianni AM and Di Nicola M: Improved clinical outcome in indolent B-cell lymphoma patients vaccinated with autologous tumor cells experiencing immunogenic death. Cancer Res 70: 9062-9072, 2010.

31. Fucikova J, Kralikova P, Fialova A, Brtnicky T, Rob L, Bartunkova J and Spísek R: Human tumor cells killed by anthracyclines induce a tumor-specific immune response. Cancer Res 71: 4821-4833, 2011.

32. Tesniere A, Schlemmer F, Boige V, Kepp O, Martins I, Ghiringhelli F, Aymeric L, Michaud M, Apetoh L, Barault L, et al: Immunogenic death of colon cancer cells treated with oxaliplatin. Oncogene 29: 482-491, 2010.

33. Zitvogel L, Kepp O, Senovilla L, Menger L, Chaput N and Kroemer G: Immunogenic tumor cell death for optimal anticancer therapy: The calreticulin exposure pathway. Clin Cancer Res 16: 3100-3104, 2010.

34. Obeid M, Tesniere A, Ghiringhelli F, Fimia GM, Apetoh L, Perfettini JL, Castedo M, Mignot G, Panaretakis T, Casares N, et al: Calreticulin exposure dictates the immunogenicity of cancer cell death. Nat Med 13: 54-61, 2007.

35. Bruchard M, Mignot G, Derangère V, Chalmin F, Chevriaux A, Végran F, Boireau W, Simon B, Ryffel B, Connat JL, et al: Chemotherapy-triggered cathepsin $\mathrm{B}$ release in myeloid-derived suppressor cells activates the Nlrp3 inflammasome and promotes tumor growth. Nat Med 19: 57-64, 2013.

36. Suzuki Y, Mimura K, Yoshimoto Y, Watanabe M, Ohkubo Y, Izawa S, Murata K, Fujii H, Nakano T and Kono K: Immunogenic tumor cell death induced by chemoradiotherapy in patients with esophageal squamous cell carcinoma. Cancer Res 72: 3967-3976, 2012.

37. Tumeh PC, Harview CL, Yearley JH, Shintaku IP, Taylor EJ, Robert L, Chmielowski B, Spasic M, Henry G, Ciobanu V, et al: PD-1 blockade induces responses by inhibiting adaptive immune resistance. Nature 515: 568-571, 2014.

38. Twyman-Saint Victor C, Rech AJ, Maity A, Rengan R, Pauken KE, Stelekati E, Benci JL, Xu B, Dada H, Odorizzi PM, et al: Radiation and dual checkpoint blockade activate non-redundant immune mechanisms in cancer. Nature 520: 373-377, 2015.

This work is licensed under a Creative Commons Attribution-NonCommercial-NoDerivatives 4.0 International (CC BY-NC-ND 4.0) License. 